\title{
High density linkage disequilibrium maps of chromosome I 4 in Holstein and Angus cattle
}

\author{
Elisa Marques ${ }^{1}$, Robert D Schnabel ${ }^{2}$, Paul Stothard ${ }^{1}$, Davood Kolbehdari ${ }^{1}$, \\ Zhiquan Wang ${ }^{1}$, Jeremy F Taylor ${ }^{2}$ and Stephen S Moore*1
}

\begin{abstract}
Address: ${ }^{1}$ Department of Agricultural, Food and Nutritional Science, University of Alberta, Edmonton, AB, T6G 2P5, Canada and ${ }^{2}$ Division of Animal Science, University of Missouri, Columbia, Missouri, 65211, USA

Email: Elisa Marques - emarques@ualberta.ca; Robert D Schnabel - schnabelr@missouri.edu; Paul Stothard - stothard@ualberta.ca; Davood Kolbehdari - kolbehda@ualberta.ca; Zhiquan Wang - zhiquan.wang@afhe.ualberta.ca; Jeremy F Taylor - taylorjerr@missouri.edu; Stephen S Moore* - stephen.moore@afhe.ualberta.ca

* Corresponding author

Published: 8 July 2008

BMC Genetics 2008, 9:45 doi:10.1 186/I47|-2156-9-45

Received: 10 October 2007

Accepted: 8 July 2008

This article is available from: http://www.biomedcentral.com/I47I-2/56/9/45

(C) 2008 Marques et al; licensee BioMed Central Ltd.

This is an Open Access article distributed under the terms of the Creative Commons Attribution License (http://creativecommons.org/licenses/by/2.0), which permits unrestricted use, distribution, and reproduction in any medium, provided the original work is properly cited.
\end{abstract}

\begin{abstract}
Background: Linkage disequilibrium (LD) maps can provide a wealth of information on specific marker-phenotype relationships, especially in areas of the genome where positional candidate genes with similar functions are located. A recently published high resolution radiation hybrid map of bovine chromosome 14 (BTAI4) together with the bovine physical map have enabled the creation of more accurate LD maps for BTAI4 in both dairy and beef cattle.
\end{abstract}

Results: Over 500 Single Nucleotide Polymorphism (SNP) markers from both Angus and Holstein animals had their phased haplotypes estimated using GENOPROB and their pairwise $r^{2}$ values compared. For both breeds, results showed that average LD extends at moderate levels up to 100 kilo base pairs (kbp) and falls to background levels after $500 \mathrm{kbp}$. Haplotype block structure analysis using HAPLOVIEW under the four gamete rule identified 122 haplotype blocks for both Angus and Holstein. In addition, SNP tagging analysis identified 410 SNPs and 420 SNPs in Holstein and Angus, respectively, for future whole genome association studies on BTAI4. Correlation analysis for marker pairs common to these two breeds confirmed that there are no substantial correlations between $\mathrm{r}$-values at distances over $10 \mathrm{kbp}$. Comparison of extended haplotype homozygosity $(E H H)$, which calculates the LD decay away from a core haplotype, shows that in Holstein there is long range LD decay away from the DGATI region consistent with the selection for milk fat \% in this population. Comparison of EHH values for Angus in the same region shows very little long range LD.

Conclusion: Overall, the results presented here can be applied in future single or haplotype association analysis for both populations, aiding in confirming or excluding potential polymorphisms as causative mutations, especially around Quantitative Trait Loci regions. In addition, knowledge of specific LD information among markers will aid the research community in selecting appropriate markers for whole genome association studies. 


\section{Background}

In previous studies, large variations in linkage disequilibrium (LD) have been reported [1-5]. Different measures of LD such as $\mathrm{r}^{2}$ and $\mathrm{D}^{\prime}$ are known to yield different conclusions in terms of the extent of LD. In studies using microsatellites and D' as a primary measure of LD [1-3] it was reported that $\mathrm{LD}$ extended for several megabases. On the other hand, when $\mathrm{r}^{2}$ was used, LD was shown to be at background levels ( $\mathrm{r}^{2}$ at approximately 0.1 ) after only 500 kilo bases pairs (kbp) [4,5]. Differences in marker types used in these studies are also potential causes for LD variation, with microsatellites being more suitable for detecting long range LD than SNPs [6].

High resolution LD maps can provide information on specific markers that are part of haplotype blocks used in association analysis [4,7]. Previous whole genome linkage disequilibrium maps in cattle $[5,7]$ have been used to analyze different aspects of LD. In the case of McKay et al. [5], approximately 3,000 markers (microsatellites and SNPs) were used to assess the extent of LD in eight different cattle breeds, while Khatkar et al. [7] analyzed the haplotype block diversity in Holstein-Friesan cattle using approximately 15,000 SNPs. The latter also used the Btau_3.1 build to arrange markers along the genome, however it is now known that BTAu_3.1 build has inconsistencies with other independently built cattle maps $[8,9]$.

In addition, such LD maps can be considered a crucial tool for researchers looking to confirm or exclude potential polymorphisms as causative mutations. Recent studies using breed specific LD information have shed light on the importance of using LD information to link potential markers to economically relevant traits in cattle. In 2007, Olsen et al. [10] reported that a mutation in ABCG2, a gene responsible for secreting important substrates into milk [11], is the most likely candidate for affecting the observed milk yield quantitative trait loci (QTL) on BTA6 [12]. The approach used included constructing a dense marker map spanning the QTL region and using linkage and linkage disequilibrium information to assess polymorphisms in ABCG2 and other genes.

Correct marker order is crucial for construction of linkage disequilibrium and haplotype maps, as well as for future candidate gene searches on chromosomes harboring economically important traits. Bovine chromosome 14 (BTA14) is widely known to harbor quantitative trait nucleotides (QTN) with large effect on milk fat percentage [13] and marbling [14]. In addition, several QTL affecting other economically important traits have been identified on BTA14 $[15,16]$.

This study focuses on the comparison of linkage disequilibrium $\left(\mathrm{r}^{2}\right)$ between Holstein and Angus cattle using over
500 BTA14 single nucleotide polymorphism (SNP) markers on 331 Holstein and 137 Angus animals. As well, it identifies specific haplotype blocks and tagged SNPs for BTA14 which will be useful for future whole genome association studies.

\section{Results and discussion}

Markers were binned according to marker distances (kbp) and $\mathrm{r}^{2}$ was averaged and plotted for each category (Figure $1)$. LD drops from an average of 0.687 for Holstein and 0.648 for Angus to 0.328 and 0.317 , respectively, when going from $1 \mathrm{kbp}$ to $50 \mathrm{kbp}$ marker distance in both breeds. Moderate levels of LD ( $\mathrm{r}^{2}$ at approximately 0.2$)$ are reached at around $100 \mathrm{kbp}$ and background levels $\left(\mathrm{r}^{2}\right.$ at approximately 0.1 ) at around $500 \mathrm{kbp}$. Both breeds show an inverse relationship between LD and marker distance, confirming recent studies on $\mathrm{r}^{2}$ measures in cattle $[4,5]$. The average $r^{2}$ value for Holstein in McKay et al. [5] was higher (0.91) than in our study (0.687) for the $1 \mathrm{kbp}$ inter-marker distance. This difference in value can be attributed to the wide range $(0.005$ to 1$)$ in LD in our study (Additional file 1). McKay et al. [5] calculated LD using 81 markers for BTA14 compared to 502 in our study. The range in LD in our study is most likely a result of sampling of gametes to form successive generations [17] which is dependent on finite population size and not so much on the sample size. In this case, there could have been ancestral recombination between certain markers in close proximity, but not others. This is plausible, in the case of maternal haplotypes, when one considers the complexity of the pedigrees for both populations, with dams sometimes contributing information to multiple families. Another important aspect to mention in this analysis is the half-sib relationship among some dams in the Holstein population, causing slightly inflated LD values. In addition to these findings, there is a more rapid decline in LD for Angus compared to Holstein overall. Differences in effective population sizes for both breeds are a plausible explanation for this observed difference.

There are a number of algorithms used to define haplotype blocks [18-21]. The confidence interval algorithm [19] used by Khatkar et al. [7] relies on D' measures between markers to define blocks. The other approach used in LD analysis in dogs [22] and more recently in cattle [4] utilizes the four gamete rule [23] which defines blocks based on all 4 possible two-marker haplotypes existing with observed frequencies of at least 0.01. Using this method incorporated in HAPLOVIEW [24], 122 blocks (33 bp to $1338 \mathrm{kbp}$ ) were identified in Holstein and 122 blocks (45 bp to $1767 \mathrm{kbp}$ ) were identified in Angus (Figure 2, 3 and Additional file 2). The confidence interval method used by Khatkar et al. [7] found 27 blocks for BTA14. When the D' method was applied to our data, 64 blocks (33 bp to $1126 \mathrm{kbp}$ ) were identified in Holstein 


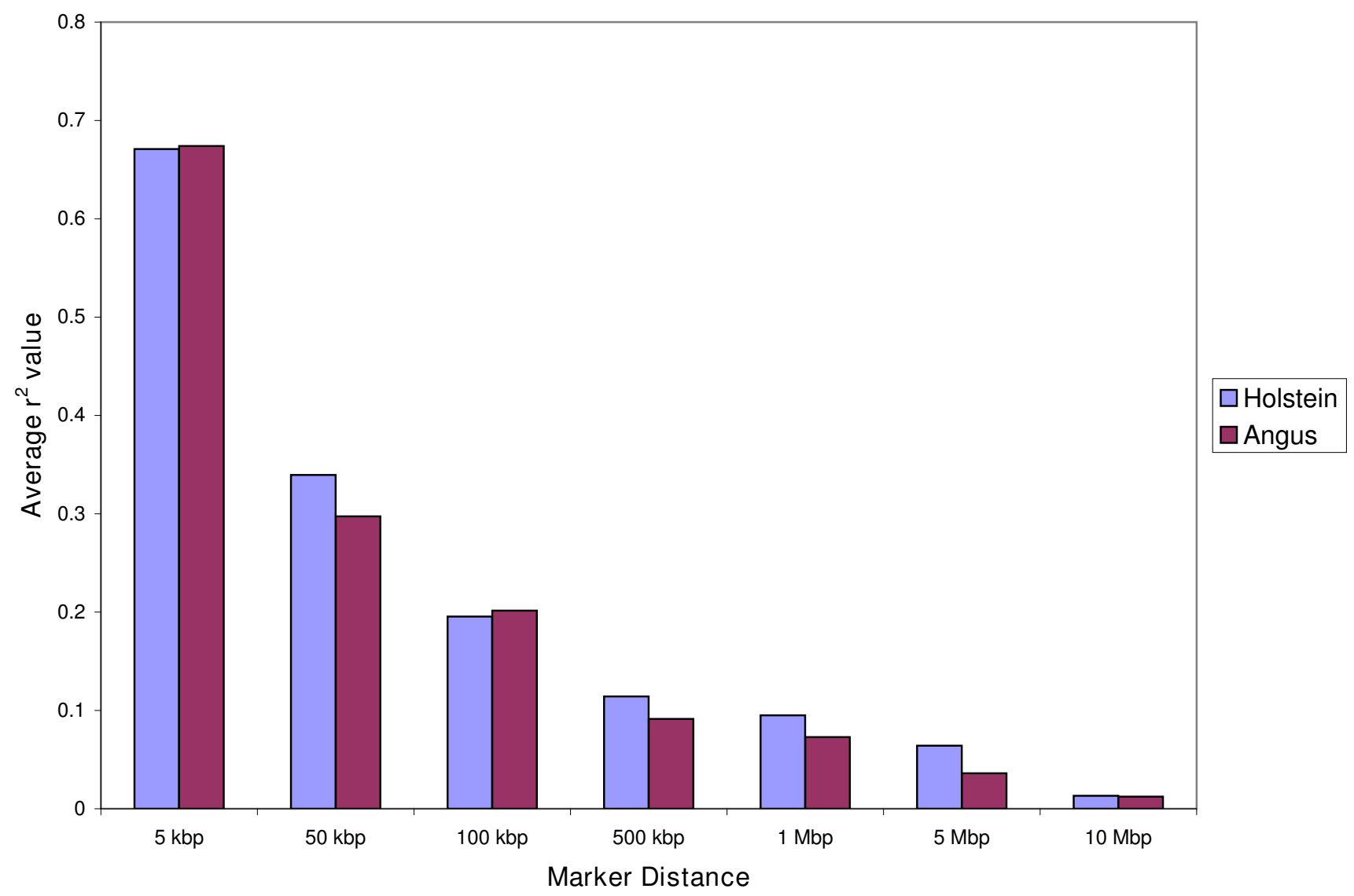

Figure I

Bovine chromosome I 4 (BTAI4) marker detail. Average $r^{2}$ value for different marker distances (kbp) using 509 SNPs on Angus and 502 SNPs on Holstein animals.

and 47 blocks ( 45 bp to $815 \mathrm{kbp}$ ) were identified in Angus (data not shown). Khatkar et al. [7] included 303 BTA14 markers on Holstein-Friesan cattle compared to 502 BTA14 markers in this study, so it is expected that as the number of markers increases more haplotype blocks are identified [25]. However, Khatkar et al. [7] not only used a different haplotype finding method, but also a different marker order causing differences in the number of blocks found. Another difference to take into consideration is that our haplotype block evaluation did not focus on coding regions, unlike Khatkar et al. [7]. Indeed, knowledge of LD within candidate genes is important, however noncoding elements such as miRNAs might also play a role in many inherited traits [26].

It is important to note that even though the extent of LD between these two breeds is similar, implementation of marker assisted selection based on the information from one breed cannot always be used for the other. In some cases, two markers at the same distance can show similar $\mathrm{r} 2$ values in different breeds, but can be in different LD phase. For example: BTA-113824 and BTA-113826 have r2 value of 0.988 in Holstein and 0.923 for Angus (Additional file 1 ). In order to verify if the same phase of LD between markers persisted for both breeds, the correlation of $r$ values was calculated including all the same markers genotyped on both breeds. In order for markers to be in the same LD phase in both breeds, the r statistic has to be the same (value and sign) in both breeds [27]. Correlation of $\mathrm{r}$ statistic between Holstein and Angus indicates that a high correlation persists up to $10 \mathrm{kbp}$ (Figure 4 and Additional file 3), agreeing with results from Goddard et al. [27]. This is not surprising since LD phase is less likely to be preserved between different breeds for longer distances. Therefore, careful examination of linkage disequilibrium measurement is necessary before applying genomic selection using the same SNP markers across these breeds.

Identification of haplotype blocks can be very useful in planning for association studies. The idea of selecting the minimum number of SNPs that define a particular haplo- 


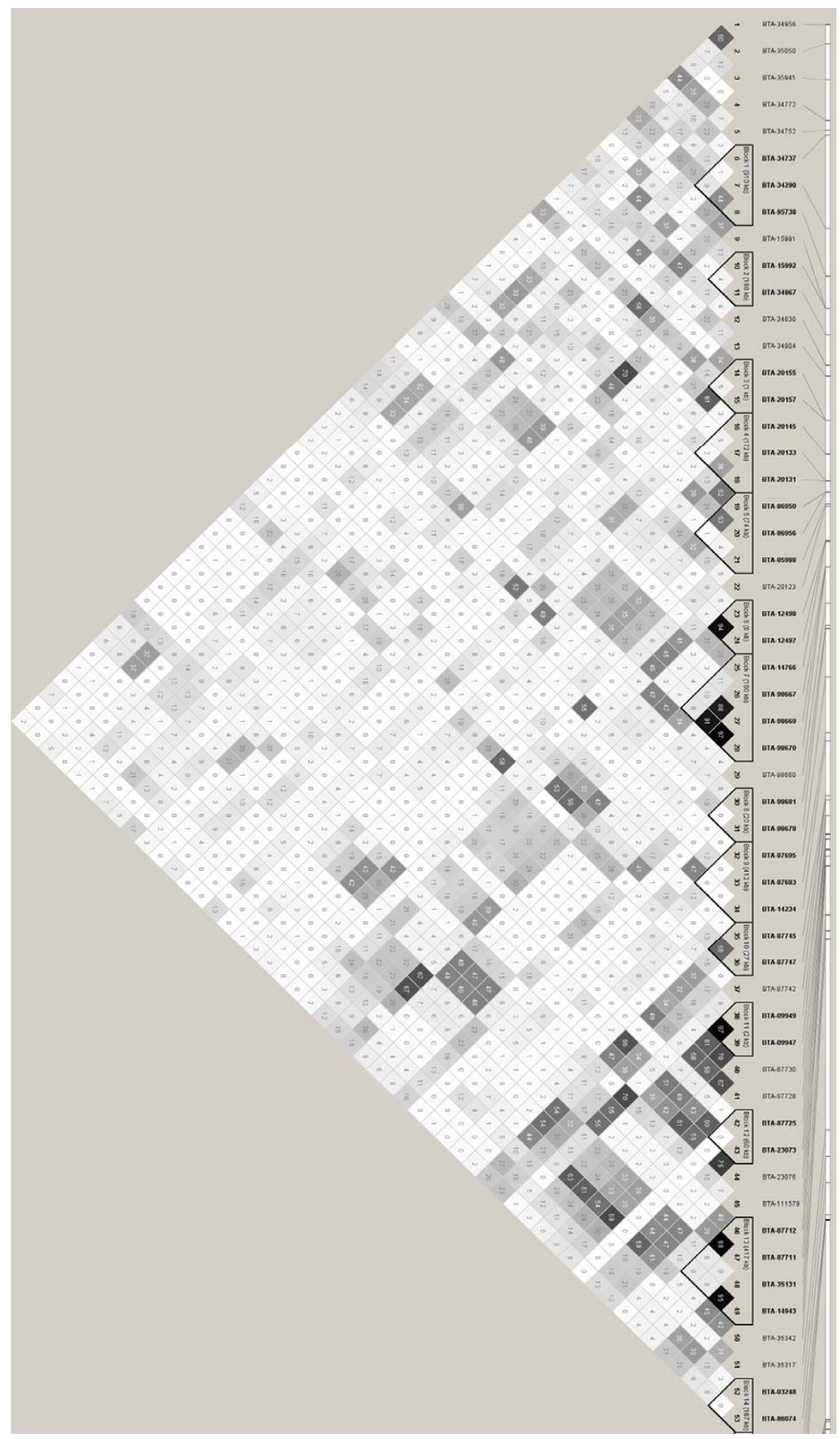

Figure 2

Linkage disequilibrium (LD) map for Holstein cattle. LD map of 502 SNP markers on Holstein cattle created using HAPLOVIEW [24]. For legibility purposes, only the first 53 markers are represented. The dark squares represent high $r^{2}$ values and triangles surrounding markers represent haplotype blocks under the four gamete rule [23]. A complete list of haplotype blocks is in Additional file 2. 


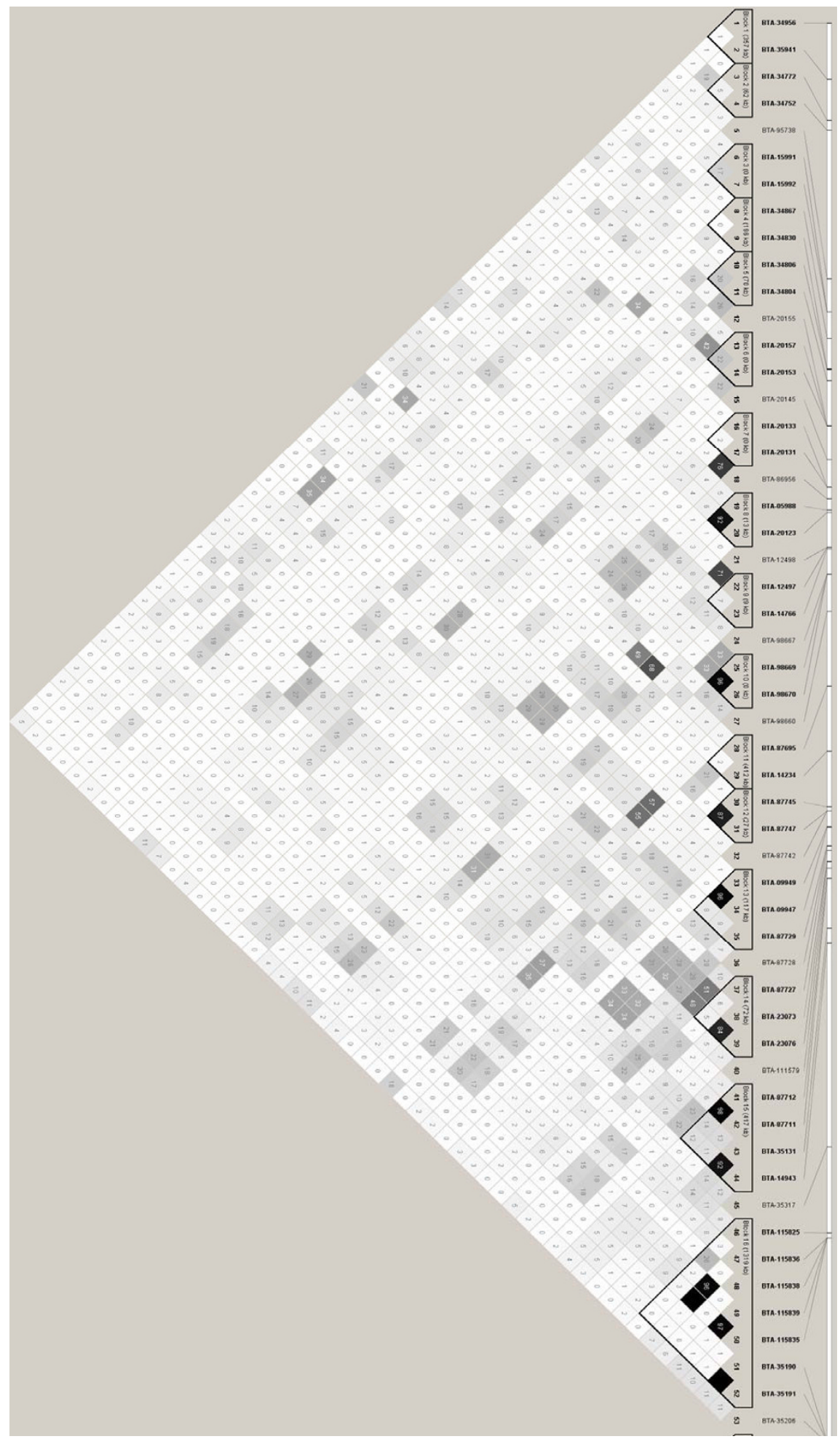

Figure 3

Linkage disequilibrium (LD) map for Angus cattle. LD map of 509 SNP markers on Angus cattle created using HAPLOVIEW [24]. For legibility purposes only the first 53 markers are represented. Dark squares represent high $r^{2}$ values and triangles surrounding markers represent haplotype blocks under the four gamete rule [23]. A complete list of haplotype blocks is in Additional file 2. 


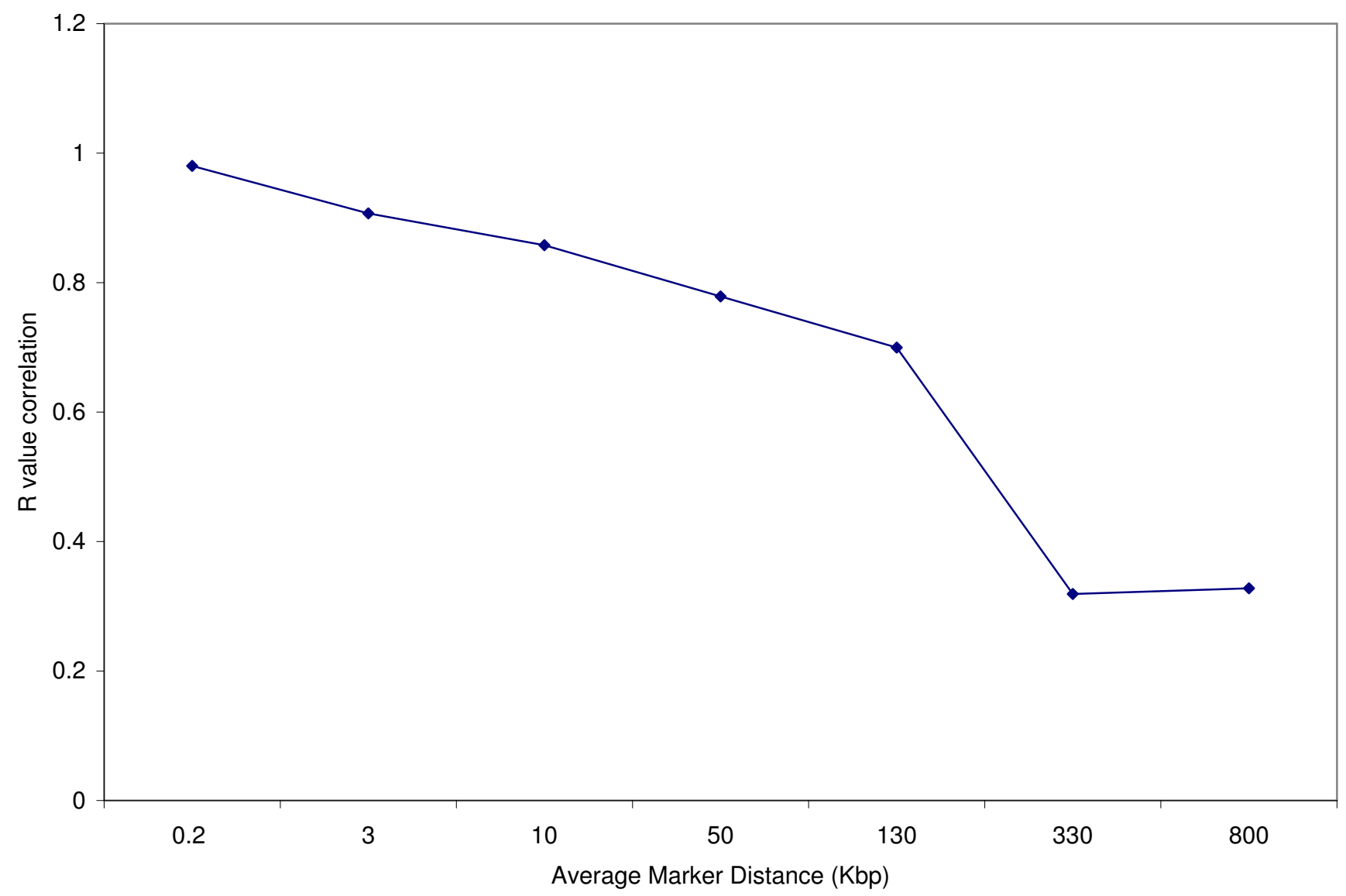

\section{Figure 4}

Graph depicting the correlation of $r$-value for Holstein and Angus cattle. Correlation of $r$-values between Holstein and Angus using 419 markers genotyped on both breeds. Values are plotted against average marker distances (kbp). R-values are presented in Additional file 3.

type of interest has been widely used in human genetics [21,24,28-31]. Together, haplotype blocks and SNP tagging focus on reducing the number of SNPs required for future association studies; thereby decreasing the cost associated with genotypes without the loss of precision in those studies. Using the tagger option [32] incorporated in HAPLOVIEW, 410 SNP markers were tagged in Holstein and 420 in Angus (Additional file 1). Briefly, this procedure defines a threshold for $\mathrm{r}^{2}$ (default: 0.8 ) and SNPs tagged have LD measure higher than the threshold set. Of the total number tagged, 304 markers are common to both breeds. Using this approach, Hayes et al. [33] identified sites of preferential recombination when evaluating SNPs in four casein genes in goat milk. They were able to tag 11 SNPs that form part of different haplotypes, thereby reducing the cost of haplotype assisted selection (HAS) while identifying specific haplotypes associated with protein and fat percentage as well as milk volume.
Minor allele frequencies (MAFs) plotted against marker distances were used to observe any trends in decreased MAF. Such regions can indicate areas where alleles are reaching fixation, possibly because of selective pressure. In Holstein, acyl-CoA:diacylglycerol acyltransferase 1 (DGAT1) lysine variant has been increasingly selected for in this breed [13] due to its association with increased milk fat $\%$. This frequency can vary between populations depending on the breeding goal implemented (high or low milk fat \%) [34]. Using human coordinates from Marques et al. [8], the region between SNPs BTA-35050 and BTA-35941 were shown to be flanking the location of DGAT1. Calculation MAFs in this region showed an average MAF equal to 0.43 (Additional file 1). When analyzing nearby regions, a small cluster of low MAF SNPs is observed $7400 \mathrm{kbp}$ away (Additional File 4). Considering our average estimate of LD reaching background levels $\left(\mathrm{r}^{2}\right.$ at approximately 0.1 ) at $500 \mathrm{kbp}$ inter-marker distance, it is unlikely that these particular SNPs are in high LD with alleles from DGAT1; thereby implying that a higher den- 
sity set of markers is needed in this region in order to make conclusions regarding the allele frequency trends around DGAT1. Screening the Angus breed for obvious signs of low MAF, approximately at the $30 \mathrm{Mbp}$ region showed a cluster of low MAF SNPs (Additional file 5). These SNPs are located approximately $0.5 \mathrm{Mbp}$ from a region of BTA14 where a carcass weight QTL has been detected [15].

In order to evaluate and compare the extent of LD for a candidate region between both Holstein and Angus animals, the extended haplotype homozygosity (EHH) approach [35] was used. Analyzing the extent of LD decay at various distances away from a specific candidate region can give insights into the selection histories of populations [36]. Basically, the EHH of an unselected allele increased to a specific frequency under neutrality will be different from the EHH of a selected allele raised to the same frequency under selection pressure. The method analyses the relationship between the allele's frequency and the extent of linkage disequilibrium surrounding it. A similar approach has recently been used in studies of signatures of selection in humans population, looking for candidate genes involved in different local adaptations [37]. Haplotypes with long range LD and with high frequency signify a recent positive selection or population bottlenecks [35]. The challenge is to determine whether the signature is due to selection or effects of population demography [36]. However, regardless of the LD causes, estimating and analyzing LD within a candidate region using appropriate algorithms can indicate selection on genes within this particular region. In general, segments of the chromosome where selected alleles are located will increase in frequency in a specific population as these selected alleles are pressured to reach fixation.

In our analysis, the DGAT1 region was selected for EHH analysis and for comparison between the two breeds. In Holsteins, the second highest frequency haplotype, 33.3\% (AA) showed the highest $\mathrm{EHH}$ when plotted up to $10 \mathrm{Mbp}$ from the candidate region (Figure 5). Another haplotype, AC with a frequency of $15.1 \%$, showed steady EHH values up until approximately $4 \mathrm{Mbp}$ from the candidate region and consistently declined reaching EHH values under the AA haplotype. Within this same region, approximately 1.5 Mbp from DGAT1, lies CYP11B1, another gene linked to milk production traits in dairy cattle [38]. EHH analysis on Angus using SNPs in the same region showed little extended LD away from the candidate region (Figure 6). Haplotype AA, with frequency of $61.3 \%$, showed declining $\mathrm{EHH}$ values after approximately $600 \mathrm{kbp}$ away from the candidate region. EHH plots can be used to evaluate not only potential regions showing extended long range $\mathrm{LD}$, but also long range $\mathrm{LD}$ between two gene variants, as shown with DGAT1 in Grisart et al. [13]. In this case, EHH values for the fat increasing haplotype (lysine allele) was consistently higher than for the alanine variant.

\section{Conclusion}

Marker-phenotype association analysis coupled with information from bovine breed specific LD maps will be crucial for the research community, especially for chromosomes with extensive QTL information. Multi-locus LD can also aid in identifying specific haplotypes demonstrating long range LD decay and in determining regions in the genome where increased selection has occurred, even if the functional selection target is not known.

The increased availability of markers along with information from independently built maps will be a great aid in constructing accurate high density linkage disequilibrium and haplotype maps for a number of cattle breeds. LD information presented here should aid the community in future analysis for both Holstein and Angus breeds, possibly confirming or excluding potential polymorphisms as causative mutations, as well as increasing the power of QTL detection by selecting markers across BTA14 with specific amount of $L D$.

\section{Methods \\ Animal Resource}

Three hundred and thirty-one Holstein bulls provided by Semex Canada and one hundred and thirty seven American Angus bulls were used in this study. The Holstein bulls represent an eight generation extended pedigree. Angus families were selected to consist of one grandparent, one parent and three or more progeny. This pedigree structure has previously produced efficient estimates of phased haplotypes. Pedigree information for Holstein animals was obtained from the Animal Improvement Program Laboratory of the USDA [39]. Pedigree information for Angus bulls was provided by the American Angus Association [40].

\section{Selection and Genotyping of Markers}

Single Nucleotide Polymorphisms (SNPs) included in this study were selected from the Bovine genome project [41] previously mapped onto BTA14 according to procedures described by Marques et al. [8]. SNPs were analyzed using an Illumina BeadStation 5.2 genotyping instrument (Illumina, Inc) and SNP genotypes were assigned using BeadStudio (Illumina, Inc) software.

\section{LD Analysis}

Only markers successfully mapped on BTA14 were used in this study even if they were successfully genotyped on both breeds. Initially all 843 markers from Marques et al. [8] were genotyped. Thirty-one did not successfully amplify on both breeds. These markers were then filtered to exclude loci with a Minor Allele Frequency $(\mathrm{MAF}<0.02$ 


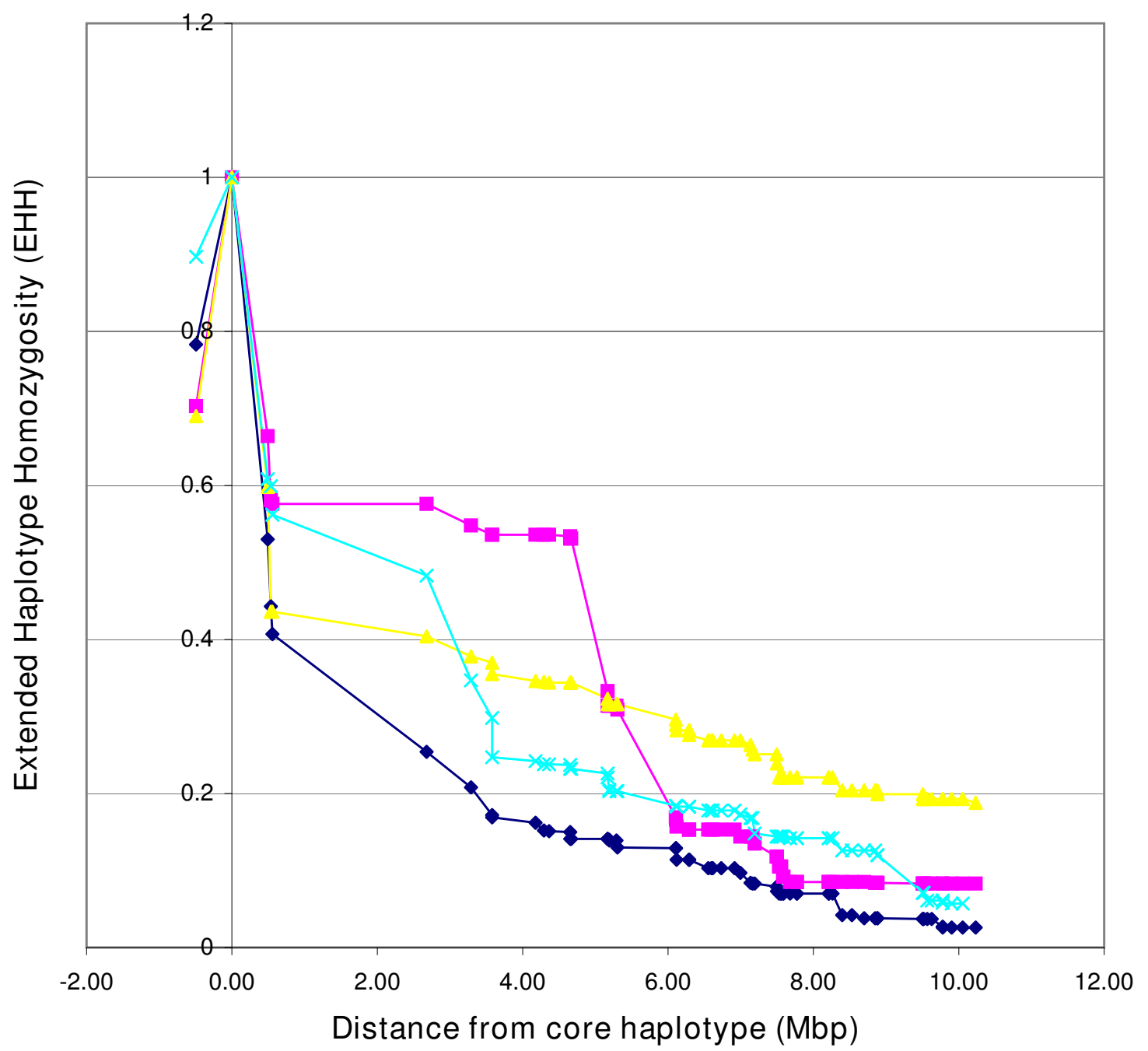

\section{Figure 5}

Extended haplotype homozygosity (EHH) graph for Holstein cattle. EHH values in Holstein evaluating the decay of LD on either side of the core haplotypes. Values plotted as a function of increasing marker distance. Markers BTA-35050 and BTA-3594I were used to make up the candidate region near acyl-CoA:diacylglycerol acyltransferase I (DGATI). Marker positions are represented in mega base pair (Mbp). The pink plot represents haplotype AC with I5.I\% frequency. The blue plot represents haplotype GA with $16.9 \%$ frequency. The yellow plot represents haplotype AA with $33.7 \%$ frequency. The light blue plot represents haplotype GC with $34.3 \%$ frequency.

or that had greater than $10 \%$ missing genotypes within a breed This filtering resulted in 518 and 505 candidate loci in Angus and Holstein respectively which were used for further analysis. Genotype quality and haplotypes were estimated with GENOPROB $2.0[42,43]$ using the map coordinates of Marques et al. [8] and the extended pedigree relating all animals within each breed. GENOPROB estimates the probability that a genotype is correct (pGmx) as well as identifies the most likely phase relationship between the alleles. Only high probability (pGmx $\geq 0.95$ ) genotypes were considered for further analysis with no restriction used for order probability.
Recent reports on GENOPROB showed that Holstein and Angus breeds produced the most accurately estimated genotypes and phased chromosome due to their complex pedigree structure [5]. Once paternal and maternal haplotypes were estimated they were inserted onto HAPLOVIEW [24] to verify their quality. The settings used included: min genotyped \%: 50, Hardy Weinberg (HW) pvalue cutoff: 0.0010 , Minimum minor allele freq: 0.0010 , Maximum \# Mendel errors: 1. Overall, 9 markers dropped out from the Angus genotypes and 3 from Holstein. Markers passing the above filtering criteria were used to estimate LD using only the maternal haplotype and the 


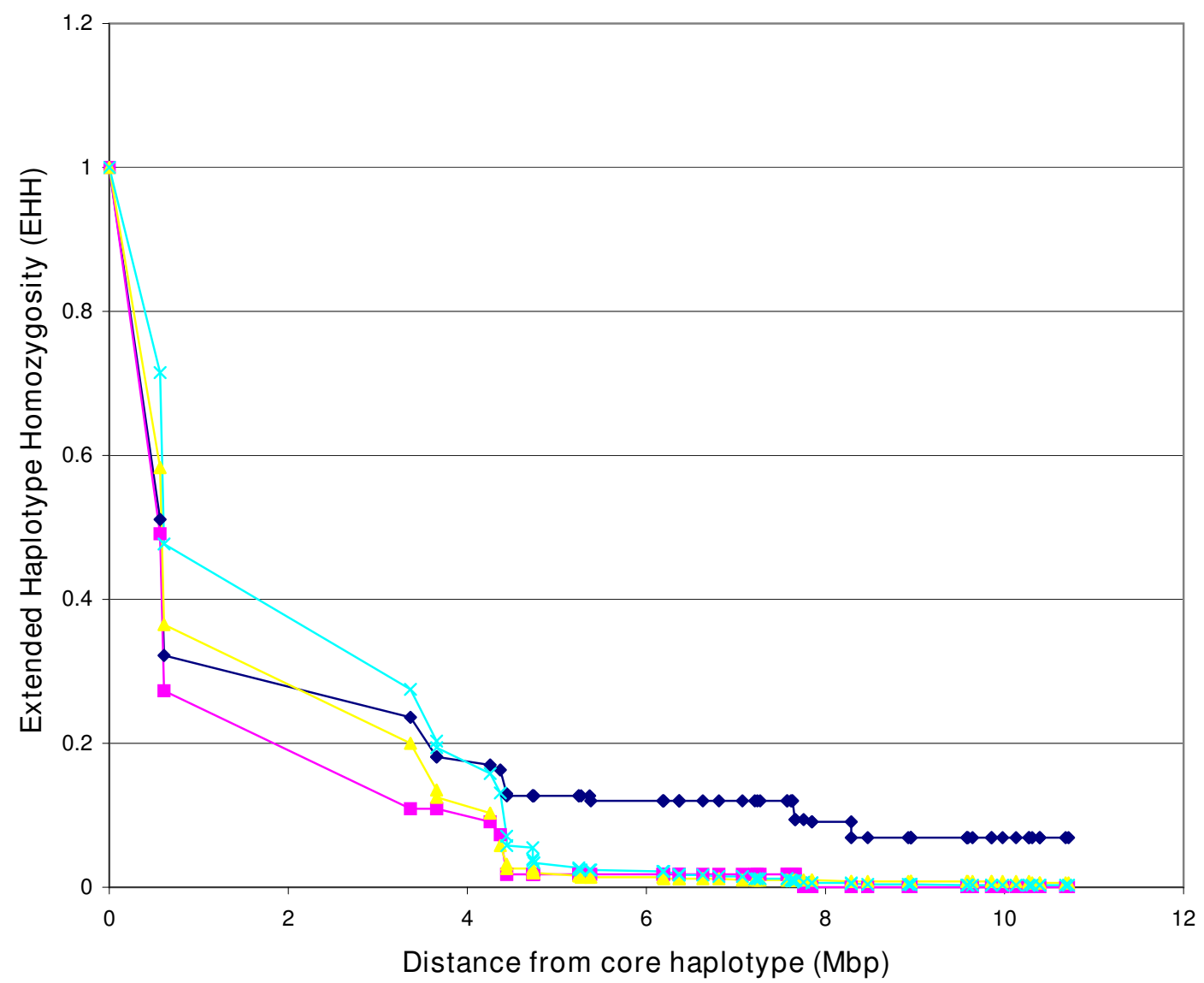

\section{Figure 6}

Extended haplotype homozygosity (EHH) graph for Angus cattle. EHH values in Angus evaluating the decay of LD on either side of the core haplotypes. Values are plotted as a function of increasing marker distance on Angus cattle. Markers BTA-34956 and BTA-3594I were used to make up the candidate region near acyl-CoA:diacylglycerol acyltransferase I (DGATI). Marker positions are represented in mega base pair (Mbp). The pink plot represents haplotype CC with $6.41 \%$ frequency. The blue plot represents haplotype CA with $13.9 \%$ frequency. The yellow plot represents haplotype AC with $18.5 \%$ frequency. The light blue plot represents haplotype AA with $61.3 \%$ frequency.

program HAPLOXT [44]. The average marker spacing using this subset of markers was approximately $170 \mathrm{kbp}$, with the smallest and largest gaps between markers being $0.03 \mathrm{kbp}$ and $2256.72 \mathrm{kbp}$, respectively. Maternal haplotypes were used in order to avoid biasing the linkage disequilibrium values due to the pedigree structure, which were solely paternal lineages.

Marker positions were inferred using the marker order from the $12 \mathrm{~K} \mathrm{RH}$ map of Marques et al. [8] which is in high agreement with the recently released physical map based on the independent whole genome map of Snelling et al. [9]. Preliminary comparison between our marker order and the recently published bovine sequence assembly Btau_4.0 [41] shows agreement for markers common (737 markers) to both maps. Relative bp positions were calculated by dividing the highest centiray $(\mathrm{cR})$ position by the corresponding bp position in the bovine sequence assembly Btau_3.1. The resultant average was approximately $17 \mathrm{kbp}$ per $\mathrm{CR}$. In regions where multiple markers had the same cR position, the sequence assembly distance was used. These closely mapped markers were in agreement with the assembly, according to results presented by Marques et al. [8].

Correlation of r-value used 419 markers common to both breeds. The r-value was calculated according to the formula [45]:

$$
r=\frac{\left(\text { freq }\left(A 1_{-} B 1\right)^{*} \text { freq }\left(A 2_{\_} B 2\right)-\text { freq }\left(A 1_{-} B 2\right)^{*} \text { freq }\left(A 2_{-} B 1\right)\right)}{\sqrt{\text { freq }(A 1)^{*} \text { freq }(B 1)^{*} \text { freq }(A 2)^{*} \text { freq }(B 2)}}
$$


Where A1 is the first allele of the first marker making up the haplotypes A1_B1 or A1_B2, A2 is the second allele of the first marker, $\mathrm{B} 1$ is the first allele of the second marker and B2 is the second allele of the second marker. Marker phase analysis was performed as follows: First, marker pairs had their r-values and inter-marker distances calculated. Next, the correlation of r-values (same marker pair) for each breed was calculated. Markers were then binned according to their inter-marker distance (category) and their correlation results averaged for each category. Haplotype and allele frequencies were calculated using SAS version 1.1.3 (SAS, Inc). Additional file 3 provides a list of markers and their calculated r-value for both breeds in each marker distance category.

Calculation of extended haplotype homozygosity (EHH) was performed using a EHH calculation web tool [46] designed according to procedures described by Sabeti et al. [35]. Only maternal haplotypes were loaded.

\section{Authors' contributions}

EM collected the genotypes, analyzed the data and drafted the manuscript. RDS phased the genotypes and provided intellectual support. PS aligned sequences against the bovine sequence assembly. DK participated in the data extraction. ZW compiled SNP markers and designed genotyping assay. JFT provided Angus samples and SSM initiated and supervised the project. All authors read and approved the final manuscript.

\section{Additional material}

\section{Additional file 1}

List of markers used for Linkage Disequilibrium (LD) analysis on Holstein and Angus cattle. File includes: NCBI accession number, $12 \mathrm{~K}$ $R H$ positions [8], inferred kilo base ( $k b p)$ positions as described in the materials and methods section, pairwise $r^{2}$ data, tagged SNPs and minor allele frequencies (MAFs).

Click here for file

[http://www.biomedcentral.com/content/supplementary/14712156-9-45-S1.xls]

\section{Additional file 2}

List of haplotype blocks obtained in HAPLOVIEW [24] under the four gamete rule [23] for Holstein and Angus cattle.

Click here for file

[http://www.biomedcentral.com/content/supplementary/14712156-9-45-S2.xls]

\section{Additional file 3}

Correlation of r-statistic using 419 markers genotyped on both Holstein and Angus cattle.

Click here for file

[http://www.biomedcentral.com/content/supplementary/14712156-9-45-S3.xls]

\section{Additional file 4}

Minor Allele Frequency (MAF) for 502 SNPs genotyped on Holstein. MAFs were plotted against marker positions ( $k b p)$ on bovine chromosome 14. Red circle depicts the position of acyl-CoA:diacylglycerol acyltransferase 1 (DGAT1).

Click here for file

[http://www.biomedcentral.com/content/supplementary/14712156-9-45-S4.pdf]

\section{Additional file 5}

Minor Allele Frequency (MAF) for 509 SNPs genotyped on Angus. MAFs were plotted against marker positions ( $k b p$ ) on bovine chromosome 14. Red circle depicts the position of acyl-CoA:diacylglycerol acyltransferase 1 (DGAT1). Orange circle represents the region of low MAF near a previously identified carcass weight QTL [15] represented by a yellow line.

Click here for file

[http://www.biomedcentral.com/content/supplementary/14712156-9-45-S5.pdf]

\section{Acknowledgements}

This work was funded by Grant Number 2003A245R from Alberta Agriculture Research Institute, CDN-DairyGen/CRD 3|3675-04 and NSERC-

CRD PJ3 13675-04 awarded to S.S. Moore. The authors gratefully acknowledge the early pre-publication access under the Fort Lauderdale conventions to the draft bovine genome sequence provided by the Baylor College of Medicine Human Genome Sequencing Center and the Bovine Genome Sequencing Project Consortium.

\section{References}

I. Farnir F, Coppieters W, Arranz JJ, Berzi P, Cambisano N, Grisart B, Karim L, Marcq F, Moreau L, Mni M, Nezer C, Simon P, Vanmanshoven $P$, Wagenaar D, Georges M: Extensive genome-wide linkage disequilibrium in cattle. Genome Res 2000, 10(2):220-227.

2. Tenesa A, Knott SA, Ward D, Smith D, Williams JL, Visscher PM: Estimation of linkage disequilibrium in a sample of the United Kingdom dairy cattle population using unphased genotypes. J Anim Sci 2003, 8 I(3):617-623.

3. Vallejo RL, Li YL, Rogers GW, Ashwell MS: Genetic diversity and background linkage disequilibrium in the North American Holstein cattle population. J Dairy Sci 2003, 86(I 2):4I37-4I47.

4. Gautier M, Faraut T, Moazami-Goudarzi K, Navratil V, Foglio M, Grohs C, Boland A, Garnier JG, Boichard D, Lathrop M, Gut I, Eggen $A$ : Genetic and haplotypic structure in 14 European and African cattle breeds. Genetics 2007.

5. McKay SD, Schnabel RD, Murdoch BM, Matukumalli LK, Aerts J, Coppieters W, Crews D, Dias Neto E, Gill CA, Gao C, Mannen H, Stothard P, Wang Z, Van Tassell CP, Williams JL, Taylor JF, Moore SS: Whole genome linkage disequilibrium maps in cattle. $B M C$ Genet 2007, 8:74.

6. Varilo T, Paunio T, Parker A, Perola M, Meyer J, Terwilliger JD, Peltonen $L$ : The interval of linkage disequilibrium (LD) detected with microsatellite and SNP markers in chromosomes of Finnish populations with different histories. Hum Mol Genet 2003, I 2(I):51-59.

7. Khatkar MS, Zenger KR, Hobbs M, Hawken RJ, Cavanagh JA, Barris W, McClintock AE, McClintock S, Thomson PC, Tier B, Nicholas FW, Raadsma HW: A primary assembly of a bovine haplotype block map based on a 15,036-single-nucleotide polymorphism panel genotyped in holstein-friesian cattle. Genetics 2007, 176(2):763-772.

8. Marques E, De Givry S, Stothard P, Murdoch B, Wang Z, Womack J, Moore $S$ : $A$ high resolution radiation hybrid map of bovine chromosome 14 identifies scaffold rearrangement in the latest bovine assembly. BMC Genomics 2007, 8(I):254. 
9. Snelling WM, Chiu R, Schein JE, Hobbs M, Abbey CA, Adelson DL, Aerts J, Bennett GL, Bosdet IE, Boussaha M, Brauning R, Caetano AR, Costa MM, Crawford AM, Dalyrmple BP, Eggen A, Everts-van der Wind A, Floriot S, Gautier M, Gill CA, Green RD, Holt R, Jann O, Jones SJ, de Jong PJ, Kappes SM, Keele JW, Larkin DM, Lewin HA, McEwan IC, McKay S, Marra MA, Mathewson CA, Matukumalli LK, Moore SS, Murdoch B, Nicholas F, Osoegawa K, Roy A, Salih H, Schibler L, Schnabel R, Silveri L, Skow LC, Smith TP, Sonstegard TS, Taylor J, Tellam R, Van Tassell CP, Williams JL, Womack JE, Wye NH, Yang G, Zhao S: A physical map of the bovine genome. Genome Biol 2007, 8(8):RI65.

10. Olsen HG, Nilsen H, Hayes B, Berg PR, Svendsen M, Lien S, Meuwissen $T$ : Genetic support for a quantitative trait nucleotide in the ABCG2 gene affecting milk composition of dairy cattle. BMC Genet 2007, 8:32

II. Jonker JW, Merino G, Musters S, van Herwaarden AE, Bolscher E, Wagenaar E, Mesman E, Dale TC, Schinkel AH: The breast cancer resistance protein $B C R P$ (ABCG2) concentrates drugs and carcinogenic xenotoxins into milk. Nat Med 2005, II(2): I27-I29.

12. Georges M, Nielsen D, Mackinnon M, Mishra A, Okimoto R, Pasquino AT, Sargeant LS, Sorensen A, Steele MR, Zhao X, et al:: Mapping quantitative trait loci controlling milk production in dairy cattle by exploiting progeny testing. Genetics 1995, I 39(2): $907-920$.

13. Grisart B, Farnir F, Karim L, Cambisano N, Kim J], Kvasz A, Mni M, Simon P, Frere JM, Coppieters W, Georges M: Genetic and functional confirmation of the causality of the DGATI K232A quantitative trait nucleotide in affecting milk yield and composition. Proc Natl Acad Sci U S A 2004, 10 I (8):2398-2403.

14. Barendse W]: Assessing lipid metabolism. Patent, International Publication Number: WO 99/23248 World International Property Organization 1999.

15. Mizoshita K, Takano A, Watanabe T, Takasuga A, Sugimoto Y: Identification of a I.I-Mb region for a carcass weight $Q T L$ on bovine Chromosome 14. Mamm Genome 2005, I6(7):532-537.

16. Moore SS, Li C, Basarab J, Snelling WM, Kneeland J, Murdoch B, Hansen C, Benkel B: Fine mapping of quantitative trait loci and assessment of positional candidate genes for backfat on bovine chromosome I4 in a commercial line of Bos taurus. J Anim Sci 2003, 8 I(8): 1919-1925.

17. Weir BS, Hill WG: Effect of mating structure on variation in linkage disequilibrium. Genetics 1980, 95(2):477-488.

18. Daly MJ, Rioux JD, Schaffner SF, Hudson TJ, Lander ES: High-resolution haplotype structure in the human genome. Nat Genet 200I, 29(2):229-232.

19. Gabriel SB, Schaffner SF, Nguyen H, Moore JM, Roy J, Blumenstiel B, Higgins J, DeFelice M, Lochner A, Faggart M, Liu-Cordero SN, Rotimi C, Adeyemo A, Cooper R, Ward R, Lander ES, Daly MJ, Altshuler D: The structure of haplotype blocks in the human genome. Science 2002, 296(5576):2225-2229.

20. Greenspan G, Geiger D: Modeling haplotype block variation using Markov chains. Genetics 2006, I 72(4):2583-2599.

21. Zhang K, Deng M, Chen T, Waterman MS, Sun F: A dynamic programming algorithm for haplotype block partitioning. Proc Natl Acad Sci U S A 2002, 99(II):7335-7339.

22. Lindblad-Toh K, Wade CM, Mikkelsen TS, Karlsson EK, Jaffe DB, Kamal M, Clamp M, Chang JL, Kulbokas EJ 3rd, Zody MC, Mauceli E, Xie X, Breen M, Wayne RK, Ostrander EA, Ponting CP, Galibert F, Smith DR, Dejong PJ, Kirkness E, Alvarez P, Biagi T, Brockman W, Butler J, Chin CW, Cook A, Cuff J, Daly MJ, DeCaprio D, Gnerre S, Grabherr M, Kellis M, Kleber M, Bardeleben C, Goodstadt L, Heger A, Hitte C, Kim L, Koepfli KP, Parker HG, Pollinger JP, Searle SM, Sutter NB, Thomas R, Webber C, Baldwin J. Abebe A, Abouelleil A, Aftuck L, Ait-Zahra M, Aldredge T, Allen N, An P, Anderson S, Antoine C, Arachchi H, Aslam A, Ayotte L, Bachantsang P, Barry A, Bayul T, Benamara M, Berlin A, Bessette D, Blitshteyn B, Bloom T, Blye J, Boguslavskiy L, Bonnet C, Boukhgalter B, Brown A, Cahill P, Calixte N, Camarata J, Cheshatsang Y, Chu J, Citroen M, Collymore A, Cooke P, Dawoe T, Daza R, Decktor K, DeGray S, Dhargay N, Dooley K, Dooley K, Dorje P, Dorjee K, Dorris L, Duffey N, Dupes A, Egbiremolen $O$, Elong R, Falk J, Farina A, Faro S, Ferguson D, Ferreira $P$, Fisher S, FitzGerald M, Foley K, Foley C, Franke A, Friedrich D, Gage D, Garber M, Gearin G, Giannoukos G, Goode T, Goyette A, Graham J, Grandbois E, Gyaltsen K, Hafez N. Hagopian D, Hagos B, Hall J, Healy C, Hegarty R, Honan T, Horn A, Houde N, Hughes L,
Hunnicutt L, Husby M, Jester B, Jones C, Kamat A, Kanga B, Kells C, Khazanovich D, Kieu AC, Kisner P, Kumar M, Lance K, Landers T, Lara M, Lee W, Leger JP, Lennon N, Leuper L, LeVine S, Liu J, Liu X, Lokyitsang Y, Lokyitsang T, Lui A, Macdonald J, Major J, Marabella R, Maru K, Matthews C, McDonough S, Mehta T, Meldrim J, Melnikov A, Meneus L, Mihalev A, Mihova T, Miller K, Mittelman R, Mlenga V, Mulrain L, Munson G, Navidi A, Naylor J, Nguyen T, Nguyen N, Nguyen C, Nguyen T, Nicol R, Norbu N, Norbu C, Novod N, Nyima T, Olandt P, O'Neill B, O'Neill K, Osman S, Oyono L, Patti C, Perrin D, Phunkhang P, Pierre F, Priest M, Rachupka A, Raghuraman S, Rameau R, Ray V, Raymond C, Rege F, Rise C, Rogers J, Rogov P, Sahalie J, Settipalli S, Sharpe T, Shea T, Sheehan M, Sherpa N, Shi J, Shih D, Sloan J, Smith C, Sparrow T, Stalker J, Stange-Thomann N, Stavropoulos S, Stone C, Stone S, Sykes S, Tchuinga P, Tenzing P, Tesfaye S, Thoulutsang D, Thoulutsang Y, Topham K, Topping I, Tsamla T, Vassiliev H, Venkataraman V, Vo A, Wangchuk T, Wangdi T, Weiand M, Wilkinson J, Wilson A, Yadav S, Yang S, Yang X, Young G, Yu Q, Zainoun J, Zembek L, Zimmer A, Lander ES: Genome sequence, comparative analysis and haplotype structure of the domestic dog. Nature 2005, 438(7069):803-819.

23. Wang N, Akey JM, Zhang K, Chakraborty R, Jin L: Distribution of recombination crossovers and the origin of haplotype blocks: the interplay of population history, recombination, and mutation. Am J Hum Genet 2002, 7 I(5): I227-I234.

24. Barrett JC, Fry B, Maller J, Daly MJ: Haploview: analysis and visualization of LD and haplotype maps. Bioinformatics 2005, 2I(2):263-265

25. Casas E, Keele JW, Shackelford SD, Koohmaraie M, Stone RT: Identification of quantitative trait loci for growth and carcass composition in cattle. Anim Genet 2004, 35(I):2-6.

26. Davis E, Caiment F, Tordoir X, Cavaille J, Ferguson-Smith A, Cockett $\mathrm{N}$, Georges M, Charlier C: RNAi-mediated allelic trans-interaction at the imprinted RtII/Pegl I locus. Curr Biol 2005, I5(8):743-749.

27. Goddard ME, Hayes B, Chamberlain A, Mcpartlan H: Can the same markers be used in multiple breeds? 8th World Congr Genet Appl Livest Prod, Belo Horizonte, Brazil 2006.

28. Consortium. IHM: A haplotype map of the human genome. Nature 2005, 437(7063): 1299-1320.

29. Hinds DA, Stuve LL, Nilsen GB, Halperin E, Eskin E, Ballinger DG, Frazer KA, Cox DR: Whole-genome patterns of common DNA variation in three human populations. Science 2005, 307(57 I 2): 1072-1079.

30. Pe'er I, de Bakker PI, Maller J, Yelensky R, Altshuler D, Daly MJ: Evaluating and improving power in whole-genome association studies using fixed marker sets. Nat Genet 2006, 38(6):663-667.

31. Zhang K, Qin Z, Chen T, Liu JS, Waterman MS, Sun F: HapBlock: haplotype block partitioning and tag SNP selection software using a set of dynamic programming algorithms. Bioinformatics 2005, 2 I (I): | $3 \mid-134$.

32. de Bakker PI, Yelensky R, Pe'er I, Gabriel SB, Daly MJ, Altshuler D: Efficiency and power in genetic association studies. Nat Genet 2005, 37( I I): 12 17-1223.

33. Hayes B, Hagesaether N, Adnoy T, Pellerud G, Berg PR, Lien S: Effects on production traits of haplotypes among casein genes in Norwegian goats and evidence for a site of preferential recombination. Genetics 2006, I74(I):455-464.

34. Weller JI, Golik M, Seroussi E, Ezra E, Ron M: Population-wide analysis of a QTL affecting milk-fat production in the Israeli Holstein population. J Dairy Sci 2003, 86(6):2219-2227.

35. Sabeti PC, Reich DE, Higgins JM, Levine HZ, Richter DJ, Schaffner SF, Gabriel SB, Platko JV, Patterson NJ, McDonald G], Ackerman HC, Campbell SJ, Altshuler D, Cooper R, Kwiatkowski D, Ward R, Lander ES: Detecting recent positive selection in the human genome from haplotype structure. Nature 2002, 419(6909):832-837.

36. Sabeti PC, Schaffner SF, Fry B, Lohmueller J, Varilly P, Shamovsky O, Palma A, Mikkelsen TS, Altshuler D, Lander ES: Positive natural selection in the human lineage. Science 2006, 3 I2(5780): 1614-1620.

37. Voight BF, Kudaravalli S, Wen X, Pritchard JK: A map of recent positive selection in the human genome. PLOS Biol 2006, 4(3): $\mathrm{e} 72$.

38. Kaupe $B, B$ randt $H$, Prinzenberg EM, Erhardt $G$ : Joint analysis of the influence of CYP I I I I and DGATI genetic variation on milk production, somatic cell score, conformation, reproduction, 
and productive lifespan in German Holstein cattle. J Anim Sci 2007, 85(I): II-2I.

39. Holstein Canada [http://www.holstein.ca/english/Animallng/ani malinq.asp]

40. American Angus Association [http://www.angus.org/prl $\mathrm{pr}$ main.html]

41. Bovine Sequence Database [ftp://ftp.hgsc.bcm.tmc.edu/pub/data/ Btaurus/]

42. Thallman RM, Bennett GL, Keele JW, Kappes SM: Efficient computation of genotype probabilities for loci with many alleles: II. Iterative method for large, complex pedigrees. I Anim Sci 200I, 79(I):34-44.

43. Thallman RM, Bennett GL, Keele JW, Kappes SM: Efficient computation of genotype probabilities for loci with many alleles: $I$. Allelic peeling. J Anim Sci 200I, 79(I):26-33.

44. Abecasis GR, Cookson WO: GOLD--graphical overview of linkage disequilibrium. Bioinformatics 2000, 16(2): 182-183.

45. Hastings A: Multilocus population genetics with weak epistasis. I. Equilibrium properties of two-locus two-allele models. Genetics 1985, 109(4):799-8I2.

46. Mueller JC, Andreoli C: Plotting haplotype-specific linkage disequilibrium patterns by extended haplotype homozygosity. Bioinformatics 2004, 20(5):786-787.

Publish with Bio Med Central and every scientist can read your work free of charge

"BioMed Central will be the most significant development for disseminating the results of biomedical research in our lifetime. "

Sir Paul Nurse, Cancer Research UK

Your research papers will be:

- available free of charge to the entire biomedical community

- peer reviewed and published immediately upon acceptance

- cited in PubMed and archived on PubMed Central

- yours - you keep the copyright

Submit your manuscript here:

http://www.biomedcentral.com/info/publishing_adv.asp
BioMedcentral 